\title{
FAMILIA, DISCAPACIDAD Y SUCESIÓN POR CAUSA DE MUERTE. ALGUNAS IDEAS PARA LA NUEVA CONSTITUCIÓN DE CHILE
}

\section{FAMILY, DISABILITY AND SUCCESSION. SOME IDEAS FOR A NEW CHILEAN CONSTITUTION}

Manuel Barría Paredes*

REsumen

El presente trabajo tiene por objetivo proponer que en la nueva Constitución debe establecerse en forma especial la protección de los descendientes menores y las personas discapacitadas como integrantes de la familia. Conforme a ello, y partiendo de la base de la existencia de la libertad de disposición del causante a través de las reglas de la sucesión por causa de muerte, planteamos que las restricciones a dicha libertad deben basarse, no en la función social de la propiedad, sino, más bien, en la protección de los integrantes de la familia, siempre que ellos sean descendientes o personas con discapacidad, justificando, entonces, el paso de una asignación forzosa con naturaleza hereditaria a una de carácter alimenticia, como se ha planteado en algunos sistemas comparados.

Palabras Clave: Derecho sucesorio; función social de la propiedad; protección de la familia; personas con discapacidad, igualdad ante la ley; nueva Constitución.

\section{AbStRact}

This paper aims to propose that the new Constitution should established in a special way the protection of minors descendants and disabled

* Doctor en Derecho por la Pontificia Universidad Católica de Chile. Profesor de Derecho Civil de la Universidad de Concepción. Dirección postal: Barrio Universitario S/N, Concepción, Región del Biobío, Chile. Correo electrónico: mbarria@udec.cl

Recepción: 2021-05-18; aceptación: 2021-07-19. 
people as members of the Family. In accordance with this, and based on the existence of freedom of disposition of the deceased through the rules of succession due to death, it will be argued that restrictions on that freedom must be based not on the social function of property, but rather the protection of family members whenever they are descendants or persons with disabilities, thus justifying the transition from a forced allocation with a hereditary nature to one of a maintenance nature, as has been proposed in some compared systems.

KeYwords: Succession Law; Social function of property; Family protection; Disabled people; Equality before the Law; New Constitution.

\section{INTRODUCCIÓN}

La redacción de la nueva Carta Fundamental constituye una oportunidad para nuevamente revisar la relación que existe entre derecho privado y Constitución. En esta ocasión, consideramos necesario referirnos a aspectos ya planteados en esta relación, como la regulación de la familia, el derecho de propiedad y su vinculación con la Constitución, pero 144 agregando otros dos elementos, como la sucesión por causa de muerte y la protección de personas vulnerables, como descendientes menores y personas con discapacidad.

En ese sentido, salvo que el testador no tenga legitimarios, el causante no tiene libertad de disposición, pues ella se encuentra limitada por las asignaciones forzosas, que la componen los alimentos que se deben por ley a ciertas personas, la legítima y la cuarta de mejoras, según se establece en el art. 1167 del Código Civil. Por lo tanto, la primera cuestión a resolver será si dichas asignaciones forzosas se encuentran justificadas a partir de la Constitución. Para ello, actualmente hay que acudir al art. 19 n. 24 de la Constitución, que permite establecer restricciones a alguna de las facultades del dominio, entre ellas a la de disposición, lo cual es permitido siempre que deriven de la función social de la propiedad. Entonces habría que preguntarse si las asignaciones forzosas encuentran su justificación a partir de la llamada función social de la propiedad.

Enseguida analizamos si las asignaciones forzosas alcanzan su justificación como límite a la libertad de disposición por causa de muerte en la protección de la familia, por lo que habría que revisar si esa cautela sucesoria incorpora a todos los integrantes del grupo familiar que hoy son asignatarios forzosos o solo a quienes lo requieren. Y dentro de ellos se encuentran los descendientes menores del causante y a los que, siendo mayores, padezcan de una discapacidad que les impida valerse por sí mismos 
y que dependen económicamente del de cujus, los cuales, sin duda, requieren de la protección sucesoria ${ }^{1}$. En la actualidad no se hace referencia a ello en la Constitución vigente, pero entendemos que se debería incluir en la nueva Carta, tal como ha sido reconocida en otras Constituciones, pero también en tratados internacionales sobre derechos fundamentales, que se encuentran ratificados por Chile y se encuentran vigentes, sin que por ello se vea afectado el principio de igualdad ante la ley.

Para ello hacemos también una revisión de las Constituciones latinoamericanas y algunas europeas, como también los tratados internacionales sobre derechos fundamentales ratificados por nuestro país y que se encuentran vigentes vinculados a esta materia, con apoyo de la doctrina comparada y alguna jurisprudencia destacada, tanto del Tribunal Constitucional como también de nuestros tribunales superiores de justicia.

\section{LA RELACIÓN ENTRE FAMILIA Y PROPIEDAD Y SU PROYECCIÓN AL DERECHO SUCESORIO}

La legislación civil decimonónica trató en general dentro de sus Códigos Civiles, tanto al derecho de familia como al derecho de propiedad. En el caso de Chile, se dedicó el libro I a la regulación de materias vinculadas a la persona y a la familia y el libro II al derecho de propiedad y otros derechos reales. Pero la relación de la propiedad y la familia también se vislumbra en otras materias. Así, el libro IV reguló el régimen matrimonial de sociedad conyugal y con la entrada en vigencia de la Ley n. ${ }^{\circ} 19335$ se agregó el régimen matrimonial de participación en los ganancia$\mathrm{les}^{2}$.

Sin embargo, quizá donde se plasma como mayor nitidez la relación entre familia y propiedad, es en el libro III, denominado "De la sucesión por causa de muerte y de las donaciones entre vivos", lo que ha llevado a señalar a Ramón Domínguez Benavente:

"Después de haber tratado el Código Civil, en el Libro I, el derecho de familia y el derecho de la personalidad, ramas muy importantes del Derecho Civil, y en el siguiente el derecho de los bienes, parte fundamental del Derecho Patrimonial -la otra gran división

${ }^{1}$ Por lo tanto, para efectos de este trabajo, no nos referiremos a la protección sucesoria de otros integrantes de la familia, como el cónyuge o conviviente civil sobreviviente ni tampoco a los ascendientes del causante.

${ }^{2} \mathrm{Y}$ ello se manifestó también con anterioridad, en varios cuerpos normativos que hoy no se encuentran vigentes. Véase Peñallillo (2019), pp. 402-412. 
del estudio del Derecho Civil-, se ha destinado el Libro III a la sucesión por causa de muerte, es decir, al Derecho Sucesorio, desde que su estudio no forma parte propiamente del derecho de los bienes, como se afirma por Claro Solar, sino que es más bien la coronación tanto del derecho de propiedad como del Derecho de Familia, que son sus supuestos necesarios"3,

o como indica Graciela Medina: "El derecho de sucesiones es un derecho dependiente del derecho de familia y del derecho patrimonial"4.

Justamente, la estrecha vinculación entre estas dos esferas del derecho privado se manifiesta de modo fundamental en la elección de los asignatarios y su protección a través de las asignaciones forzosas, que implica que, existiendo dichos beneficiarios, se limita la libertad del causante para disponer de sus bienes a través del testamento. Y en la actualidad esta protección se demuestra, además, por cuanto se ha extendido el elenco de asignatarios forzosos, incluyendo entre ellos a todos los hijos, cualquiera sea su filiación, al cónyuge sobreviviente y también al conviviente civil sobreviviente, por lo que la cautela sucesoria no solo alcanza a la familia fundada en el matrimonio, sino que se extiende a otras formas de familia, protección reconocida, incluso, por la jurisprudencia ${ }^{5}$.

146 De esta manera, el derecho de propiedad es la base fundamental para estructurar un determinado sistema sucesorio y el codificador, siguiendo los postulados del derecho francés, le da preponderancia a la propiedad individual considerándola como "un instrumento imprescindible del desarrollo económico, desconfiando de los obstáculos que pudieran introducírsele en las leyes" ${ }^{\prime}$. Pero, además, de la propia definición del derecho de propiedad del art. 582 del Código Civil, se refleja la opción del legislador para que el titular tenga las más amplias facultades sobre la cosa, esto es, el uso, goce y la disposición, sin más limitaciones que la ley o el derecho ajeno.

Por lo tanto, el principio es que toda persona pueda disponer libremente de las cosas que son de su dominio. Sin embargo, esta libertad se limita con fuerza a través de las asignaciones forzosas ${ }^{7}$, cuando se trata de disponer

${ }^{3}$ Domínguez (1956), p. 562.

${ }^{4}$ Medina (2019), p. 219.

${ }^{5}$ Así, la Corte Suprema, refiriéndose a la noción de familia, ha indicado: "Se sostiene que se debe reconocer que la familia, en sentido amplio, pasa a designar un conjunto extenso de personas, en el que se incluyen hasta individuos que no conviven en el núcleo familiar o que no cuentan con una vinculación de parentesco con la pareja fundadora...”, Z. L. con Z. L. (2018), cons. 3. .

${ }^{6}$ TAPIA (2005), pp. 144-145.

${ }^{7}$ De acuerdo con el art. 1167: "Asignaciones forzosas son las que el testador está obligado a hacer, y que se suplen cuando no las ha hecho, aun con perjuicio de sus disposiciones 
de sus bienes a través del testamento, en la sucesión por causa de muerte, siendo asignatarios forzosos los integrantes de la familia del causante. Por ejemplo, el art. 1182 establece que son legitimarios los hijos, personalmente o representados por su descendencia, los ascendientes y el cónyuge sobreviviente. Por su parte, son asignatarios de la cuarta de mejoras, de acuerdo con el art. 1195, los descendientes, el cónyuge sobreviviente y los ascendientes. Hay que agregar también como legitimario y asignatario de la cuarta de mejoras al conviviente civil sobreviviente, de acuerdo con lo preceptuado en el art. 16 de la Ley n. ${ }^{\circ}$ 20830, que crea en Chile el Acuerdo de Unión Civil.

De ahí entonces que se genera esa estrecha relación entre el derecho de propiedad y la familia, ya que en el caso de que el causante quiera disponer de sus bienes a través del testamento, las asignaciones forzosas distorsionan esa libertad de disposición, puesto que en caso de concurrir los integrantes de la familia que tengan la calidad de asignatarios forzosos, dicha libertad de testar se verá limitada. Como indicaba Jean Carbonnier:

"Mantener la propiedad en las familias no era sólo una visión aristocrática del antiguo régimen. Cuando el legislador contemporáneo tomó las medidas de las que hablábamos antes, para facilitar el acceso de los no propietarios a la propiedad, inmediatamente se ocupó de darle a esta pequeña propiedad un arreglo familiar. Toda nuestra ley de herencias y liberalidades es la organización de este instinto que empuja a la propiedad a estar junto a la familia" ${ }^{\text {. }}$

Por ello, una de las justificaciones que se han entregado para el establecimiento de las asignaciones forzosas, especialmente la legítima, radicaba en el principio de la "copropiedad familiar", en virtud del cual, los integrantes de la familia han contribuido a la formación de ese patrimonio familiar y, por lo tanto, ello justifica que se reserve a ellos una parte de los bienes del causante. Así, Héctor Lafaille indicaba:

"En aquellos tiempos el trabajo doméstico estaba muy desarrollado y la familia venía a formar una verdadera cooperativa, en la que el jefe era un productor autónomo ayudado por todos los miembros de la colectividad. Bien se podía decir que cuando fallecía el padre, lo que dejaba a los hijos era el producto del esfuerzo común"9.

testamentarias expresas. Asignaciones forzosas son: 1. Los alimentos que se deben por ley a ciertas personas; 2. Las legítimas; 3. La cuarta de mejoras en la sucesión de los descendientes, de los ascendientes y del cónyuge.

${ }^{8}$ Carbonnier (2001), p. 384.

${ }^{9}$ Lafaille (1932), p. 144. 
Pero, además, existen otras materias en que se manifiesta la protección de la familia, asegurando ciertos bienes para su manutención. Es lo que ocurre con los llamados "bienes familiares", incorporados en Chile también por la Ley n. ${ }^{\circ}$ 19335. El art. 141 indica:

"El inmueble de propiedad de cualquiera de los cónyuges que sirva de residencia principal de la familia, y los muebles que la guarnecen, podrán ser declarados bienes familiares [...]”.

Como indicaba René Ramos:

"Con esta institución se persigue asegurar a la familia un hogar físico estable donde sus integrantes puedan desarrollar la vida con normalidad, aun después de disuelto el matrimonio"10,

lo cual ha sido reconocido, además, por diversas sentencias de la Corte Suprema, que han señalado:

"De este modo, es posible precisar que la razón que sirve de fundamento a la posibilidad de afectar bienes con el carácter de familiares, no es la existencia del matrimonio per se, sino la posibilidad de surgimiento de conflictos que ocasionen su ruptura, procurándose amparar la estabilidad de la vivienda de la familia en crisis, que si bien puede funcionar como herramienta preventiva, tiene por objeto tutelar de modo efectivo a aquellos de sus miembros que desde un punto de vista patrimonial, en relación a la habitación, queden en peor situación como consecuencia del quiebre matrimonial"11.

La misma protección, ahora especialmente al cónyuge sobreviviente, se otorga en virtud del "derecho de adjudicación preferencial", que consagra el art. $1337 \mathrm{n} .^{\circ} 10$, en virtud del cual:

"El cónyuge sobreviviente tendrá derecho a que su cuota hereditaria se entere con preferencia mediante la adjudicación a favor suyo de la propiedad del inmueble en que resida y que sea o haya sido la vivienda principal de la familia, así como del mobiliario que lo guarnece, siempre que ellos formen parte del patrimonio del difunto".

${ }^{10}$ Ramos (1995), p. 8. En el mismo sentido BrantT y Vidal (2017), p. 36.

${ }^{11}$ C. C. con P. M. (2021), cons. $6 .^{\circ}$. En el mismo sentido: N. N. con N. N. (2021), cons. $6 .^{\circ}$; R. A. con M. V. (2021), cons. $4 .^{\circ}$; V. V. con S. O. (2019), cons. $6 .^{\circ}$. 
Este derecho también lo tiene el conviviente civil sobreviviente, según el art. 19 de la Ley n. ${ }^{\circ}$ 20830, derecho que es, en esencia, asistencial. Por ello Hernán Corral sostiene:

"La protección de la vivienda familiar a favor del cónyuge tiene también una finalidad de carácter asistencial: evitar que el cónyuge quede en la calle. Podrá discutirse que ello se haga a expensas de los coherederos, pero la función de la norma es claramente esa, y allí deben reconocerse también sus límites y presupuestos" ${ }^{\prime 2}$.

Por lo tanto, podría indicarse que, a través de esta institución, se protege también a la familia, pero limitando, a su vez, el derecho de propiedad que los otros herederos tienen de la misma manera en la herencia del causante, otra manifestación de la íntima vinculación entre familia y propiedad.

\section{LA REGULACIÓN DE LA SUCESIÓN POR CAUSA DE MUERTE EN LA CONSTITUCIÓN}

La Constitución chilena no hace referencia expresa a derechos que emanan de la sucesión por causa de muerte, tal como sí lo reconocen otros sistemas comparados ${ }^{13}$. Así, la Constitución de Alemania en su art. 14 garantiza la "propiedad y el derecho de herencia, con el contenido y las limitaciones que la ley determine". El mismo reconocimiento realiza la Constitución de España, que en su art. 33 consigna también el "derecho a la propiedad privada y a la herencia”. Por su parte, la Constitución italiana, en su art. 42 indica: "La ley establecerá las normas y los límites de la sucesión legítima y testamentaria, así como los derechos del Estado en materia de sucesiones".

Por su parte, la Constitución de Francia en el art. 34 reserva a la ley regular los principios fundamentales del régimen de propiedad, de los derechos reales y de las obligaciones civiles y comerciales, donde, en todo caso, se ha planteado que:

"El valor constitucional del derecho de disponer, atributo esencial del derecho de propiedad, implica principalmente que el legislador no puede suprimir la cuota disponible o reducirla a porción

${ }^{12}$ Corral (1998), p. 234.

${ }^{13}$ Los textos de las Constituciones, tratados internacionales y otros cuerpos legales extranjeros, han sido obtenidos de sitios web oficiales de legislación de los respectivos países y disponibles en idioma español. 
congrua, y si lo hace, es una violación desproporcional a este derecho. Resulta igualmente que este derecho de disponer puede ser invocado por el legislador con el fin de justificar restricciones a otros principios y exigencias constitucionales, en particular, el eventual derecho de sucesión" ${ }^{14}$.

Más aún, el principio se encuentra reconocido en otros textos internacionales europeos, como la Carta de los Derechos Fundamentales de la Unión Europea, que en su art. 17 garantiza el derecho de propiedad y señala expresamente:

"Toda persona tiene derecho a disfrutar de la propiedad de los bienes que haya adquirido legalmente, a usarlos, a disponer de ellos y a legarlos".

Sobre la base de ello Alejandra de Lama Aymá ha señalado:

"Por tanto, aunque el art. 17.1 de la Carta no hable explícitamente del principio de libertad de testar es evidente que a ella se refiere cuando habla del derecho a disponer de los bienes (también mortis causa) y del derecho a legarlos. Además, así se desprende de las tradiciones constitucionales de los Estados Miembros en las que se recoge de forma generalizada el principio de libertad de testar" ${ }^{\prime 1}$.

Y en Latinoamérica interesante es lo que dispone el art. 402 n. ${ }^{\circ} 2$ de la Constitución de Bolivia, que establece:

"El Estado tiene la obligación de: 2. Promover políticas dirigidas a eliminar todas las formas de discriminación contra las mujeres en el acceso, tenencia y herencia de la tierra".

La herencia es también reconocida como un derecho fundamental en la Constitución de Perú, en el art. 2 n. ${ }^{\circ} 16$, que consagra el "derecho a la propiedad y a la herencia". La Constitución de Brasil en su art. 5 n. ${ }^{\circ} 30$ garantiza "el derecho a la herencia". Y, finalmente, la Constitución de Uruguay indica: "Las donaciones, herencias y legados que se le hicieren y aceptaren" serán fuentes de recursos para los gobiernos departamentales, según el art. 297 n. ${ }^{\circ} 12$.

Sin embargo, aun cuando la actual Constitución no consagra a la herencia como una garantía constitucional de manera expresa, no se puede

${ }^{14}$ Benzina (2020), p. 500.

${ }^{15}$ De Lama (2016), p. 183. 
desconocer que en forma implícita se reconoce a partir del art. 19 n. ${ }^{\circ} 24$, que establece que la Constitución asegura a todas las personas "el derecho de propiedad en sus diversas especies sobre toda clase de bienes corporales o incorporales" 16 .

Y lo anterior por cuanto se ha acuñado en la doctrina chilena la llamada teoría de la "cosificación o propietarización de los derechos", en virtud de la cual, tomando en consideración el art. 565 del Código Civil que indica: "Los bienes consisten en cosas corporales o incorporales" y que las cosas incorporales son "las que consisten en meros derechos"; el art. 576 que establece: "Las cosas incorporales son derechos reales y personales" y el art. 583 que establece: "Sobre las cosas incorporales hay también una especie de propiedad" ${ }^{17}$. Y al ser la herencia un derecho real, según lo indica de forma expresa el art. 577, los herederos tienen la propiedad sobre su herencia, derecho garantizado por la Constitución por el art. 19 n. ${ }^{\circ} 24$ ya citado, pues se reconoce el derecho de propiedad en sus diversas especies sobre toda clase de bienes corporales e incorporales, calidad que detenta el derecho real de herencia.

En cuanto a los fundamentos históricos, la protección de la propiedad privada no es originada en la actual Constitución, ya que se pueden encontrar menciones a ellas en las anteriores Cartas Fundamentales, como en la Constitución de 1925, que en su art. 10 n. ${ }^{\circ} 10$ aseguraba a todos los habitantes de la república "la inviolabilidad de todas las propiedades, sin distinción alguna"; la Constitución de 1833 que en su art. 10 n. ${ }^{\circ} 5$ establecía como garantía "la inviolabilidad de todas las propiedades, sin distinción de las que pertenezcan a particulares o comunidades [...]"; el art. 17 de la Constitución de 1828, que en su art. 17 señalaba:

"Ningún ciudadano podrá ser privado de los bienes que posee, o de aquellos a que tiene lejítimo derecho, ni de una parte de ellos por pequeña que sea [...]”.

Y este derecho de propiedad privada también se consigna en tratados internacionales ratificados por Chile y que se encuentran vigentes, como lo preceptuado en el art. 17 de la Declaración Universal de los Derechos Humanos y el art. 21 de la Convención Americana de Derechos Humanos, lo que tiene relevancia para la redacción de la nueva Constitución, puesto que la Ley n. ${ }^{\circ} 21200$, que modifica el capítulo Xv de la Constitución Política de la República, establece en el art. 135 inc. $4 .^{\circ}$ :

${ }^{16}$ Sobre el reconocimiento constitucional del derecho de propiedad en el derecho comparado véase PeñalliLlo (2014), pp. 8-24.

${ }^{17}$ Sobre esta teoría véase Domínguez (1996), pp. 127-131; PeñaIlillo (2019), pp. 113-124. 
"El texto de la Nueva Constitución que se someta a plebiscito deberá respetar el carácter de República del Estado de Chile, su régimen democrático, las sentencias judiciales firmes y ejecutoriadas y los tratados internacionales ratificados por Chile y que se encuentren vigentes",

por lo que el derecho de propiedad se mantendrá en la nueva Carta Fundamental y como consecuencia de ello, expresa o tácitamente el derecho de herencia, puesto que como indica Aurelio Barrio:

"La propiedad no es completa sino cuando resulta transmisible tanto inter vivos como mortis causa. La garantía de la herencia no deja de ser más que un corolario del reconocimiento de la propiedad privada" ${ }^{18}$.

\section{LAS LIMITACIONES AL TITULAR DEL DERECHO DE PROPIEDAD. LA FUNCIÓN SOCIAL DE LA PROPIEDAD COMO LÍMITE A LA FACULTAD DE DISPOSICIÓN POR CAUSA DE MUERTE}

El art. 582 del Código Civil define al dominio o propiedad como "el derecho real en una cosa corporal, para gozar y disponer de ella arbitrariamente; no siendo contra la ley o contra derecho ajeno". De ahí entonces que una de las facultades inherentes al dominio lo constituye con precisión la facultad de disposición que se puede ejercer mediante actos o contratos entre vivos, como también por aquellos por causa de muerte, en especial a través del testamento. Y justamente, la facultad de disposición por causa de muerte se encuentra limitada por las asignaciones forzosas, enunciadas en el art. 1167 del Código Civil.

Por su parte, el art. 19 n. ${ }^{\circ} 24$ de la Constitución establece:

"Sólo la ley puede establecer el modo de adquirir la propiedad, de usar, gozar y disponer de ella y las limitaciones y obligaciones que deriven de su función social [...]".

Por lo tanto, la ley puede establecer limitaciones a alguna de las facultades inherentes al dominio como es la de disposición, pero dicha limitación se debe fundar en lo que se denomina "función social de la propiedad". Es por ello entonces que se podría estudiar una posible tensión entre las asignaciones forzosas y la libertad de disposición y que se encuentra

${ }^{18}$ Barrio (2019), p. 289. 
establecida en el Código Civily la garantía constitucional del derecho de propiedad, puesto que, si bien dichas asignaciones no privan al causante de ejercer su facultad de disposición, la restringen y limitan, las cuales deberían justificarse constitucionalmente en virtud de la denominada "función social de la propiedad".

La Constitución no define lo que entiende por función social de la $\operatorname{propiedad}^{19}$, sino que solo hace referencia a algunas circunstancias que la configuran, como los intereses generales de la nación, la seguridad nacional, la utilidad y la salubridad públicas y la conservación del patrimonio ambiental, enumeración que se ha entendido, es de carácter taxativa ${ }^{20}$. Es entonces la jurisprudencia y la doctrina quienes se han encargado de precisar el concepto. Por ejemplo, la Corte Suprema ha señalado:

"La función social de la propiedad es una noción que permite conciliar el ejercicio del derecho de propiedad con la satisfacción de las necesidades de la comunidad para su mantenimiento y desarrollo sustentable" ${ }^{21}$.

La Constitución de 1925 hacía cierta referencia a esta función en el art. $10 \mathrm{n} .^{\circ} 10$ inc. $3 .^{\circ}$, al establecer:

"El ejercicio del derecho de propiedad está sometido a las limitaciones o reglas que exijan el mantenimiento y el progreso del orden social, y, en tal sentido, podrá la ley imponerle obligaciones o servidumbres de utilidad pública a favor de los intereses generales del Estado, de la salud de los ciudadanos y de la salubridad pública”,

disposición que fue objeto de modificación con la entrada en vigencia de la Ley n. ${ }^{\circ} 16615$ de 1967, por la cual se amplió el concepto de función social de la propiedad ${ }^{22}$. En efecto, el art. 10 n. ${ }^{\circ} 10$ fue sustituido, indicándose en la parte pertinente:

${ }^{19}$ Sobre la función social de la propiedad, véase Ríos (1987), pp. 57-73. El autor define a la función social de la propiedad, en p. 64 como: "Una limitación impuesta al ejercicio de un derecho, con el fin de asegurar que la colectividad reporte de ese manejo la satisfacción de determinadas necesidades".

${ }^{20}$ Molinera del Norte S. A. con Ministerio de Vivienda y Urbanismo (2015), cons. 60..

${ }^{21}$ Minera Pampa Fénix S. C. M. con Fisco de Chile (2016), cons. 14. ${ }^{\circ}$.

${ }^{22}$ Peralta y Yáñez (2019), pp. 36-39. En todo caso, el art. 10 n. ${ }^{\circ} 10$ de la Constitución de 1925 fue objeto de otras modificaciones en su texto, pero que no recaía en la llamada "función social de la propiedad". Estas modificaciones se incorporaron por la Ley n. ${ }^{\circ} 15295$ de 1963 y la Ley n. ${ }^{\circ} 17450$ de 1971. 
"La ley establecerá el modo de adquirir la propiedad, de usar, gozar y disponer de ella y las limitaciones y obligaciones que permitan asegurar su función social y hacerla accesible a todos. La función social de la propiedad comprende cuanto exijan los intereses generales del Estado, la utilidad y salubridad públicas, el mejor aprovechamiento de las fuentes y energías productivas en el servicio de la colectividad y la elevación de las condiciones de vida del común de los habitantes" ${ }^{23}$.

Por otra parte, el derecho constitucional comparado también ha reconocido a la función social de la propiedad para limitar las facultades del propietario. Así se establece en la Constitución de Italia, en su art. 42 y en la Constitución española, en su art. 33. Y en Latinoamérica, el art. 5 n. ${ }^{\circ} 22$ y n. ${ }^{\circ} 23$ de la Constitución de Brasil; el art. 58 de la Constitución de Colombia; la Constitución de Paraguay, en su art. 109; la Constitución uruguaya en el art. 32; la Constitución de Venezuela en su art. 115; Bolivia, en el art. 56 de su Constitución; el art. 70 de la Constitución peruana; la Constitución de Ecuador en su art. 321 y la Constitución argentina, que, si bien no lo establece en forma expresa, se extraería de sus arts. 14,17 y $19^{24}$. Y en nuestro país sucede que en la práctica, sobre la base de la función social de la propiedad, la Corte Suprema ha limitado el derecho del titular del derecho de propiedad, pero para satisfacer las necesidades de la sociedad en general y no el particular del propietario y su entorno ${ }^{25}$. La Corte Suprema estableció:

"Cuando se predica que el dueño de un predio tiene la obligación de cercar su propiedad, puede verse obviamente el asunto desde su propio interés, esto es, de impedir el ingreso de personas en su propiedad, pero también puede observarse nítidamente que otra finalidad de la preceptiva es proteger el interés de la colectividad, como será el impedir que la finca sea usada como un basural,

${ }^{23}$ Esta modificación constitucional fue la base de la actual regla sobre la función social de la propiedad. Así, se ha indicado: "En torno a este concepto se originó un prolongado debate en la Comisión de Estudio, sin que se llegara a uniformar una opinión más o menos coincidente sobre el particular. En esta contingencia se optó por mantener el criterio del constituyente de 1967, en el sentido de enumerar lo que comprende la función social sin pretender una definición”. Verdugo, Pfeffer y Nogueira (1994), p. 310.

${ }^{24}$ SAlomón (2011), p. 405.

${ }^{25}$ Lo cual también ha sido refrendado por la doctrina. Así, se ha señalado: "Tomando base en aquellos que hemos llamado principios orientadores, se ha difundido ampliamente la expresión función social de la propiedad, para advertir que el dominio (en torno al cual giran los demás derechos reales) debe ser ejercido con consideración de los intereses de la sociedad y no sólo de los particulares del propietario”. PeñaIliLlo (2019), p. 326. 
menoscabando de este modo no solo los componentes naturales del suelo y eventualmente del agua y el aire, sino que también el mismo entorno o hábitat de la vecindad" 26 .

O en otro reciente caso, en que la Corte Suprema señaló:

"La declaratoria del inmueble denominado 'Fábrica Textil Bellavista Oveja Tomé' como monumento histórico no puede ser entendido como un acto administrativo de efectos expropiatorios lo cual no es tolerado por el estatuto de la propiedad consagrado en la Carta Fundamental. Por el contrario, el decreto supremo impugnado constituye una mera limitación al derecho de dominio basado en la función social de la propiedad" ${ }^{27}$.

Y el Tribunal Constitucional ha hecho lo propio, por cuanto ha señalado:

"La función social de la propiedad es la que permite equilibrar el interés privado que alimenta y orienta el ejercicio del haz de derechos que la constituyen y el interés público que justifica su protección como derecho fundamental" ${ }^{28}$.

Como indica Eduardo Cordero:

"El propietario no sólo es titular de poderes, sino que también es sujeto pasivo de un haz de deberes que impone la función social. Dicho en otras palabras: el propietario tiene el deber y, por tanto, el poder de emplear la cosa que posee en la satisfacción de las necesidades individuales que le son propias, de emplear la cosa para el desarrollo de su actividad física, intelectual y moral, pero también tiene el deber y, por tanto, poder, de emplear la cosa que posee en la satisfacción de necesidades comunes o colectivas"29.

Por ello, es posible apreciar, a partir de la doctrina y jurisprudencia reseñada, que las limitaciones a las facultades inherentes al dominio sobre

${ }^{26}$ Fisco de Chile con Molibdenos y Metales S. A. y otra (2014), cons 4..

${ }^{27}$ Banco de Chile con Consejo de Monumentos Nacionales y otro (2020), cons. 10. .

${ }^{28}$ Molinera del Norte S. A. con Ministerio de Vivienda y Urbanismo (2015), cons. 60.. La misma consecuencia se puede extraer de otras sentencias pronunciadas por el Tribunal Constitucional, como: Agrícola San Isidro Limitada con Dirección General de Aguas (2016); S. D. con Armada de Chile (2016).

${ }^{29}$ Cordero (2008), p. 511. 
la base de la función social de la propiedad se justifican comúnmente en el interés general, por lo que entendemos que existe tensión entre las reglas sobre asignaciones forzosas como límite a la facultad de disposición del causante, que se regulan en el Código Civil, y el derecho de propiedad garantizado por la Constitución, por cuanto no es claro que las asignaciones forzosas queden incorporadas en algunas de las materias o rubros que forman parte de alguno de los elementos que configuran dicha función, como la seguridad nacional, la utilidad y salubridad pública y la conservación del patrimonio ambiental.

Pero tampoco puede quedar incorporado dentro de los intereses generales de la nación, pues como indica Enrique Evans:

"No puede transformarse el concepto intereses generales de la nación en un pozo sin fondo, donde caben todas las restricciones que el legislador quiere imponer a la propiedad"30,

lo que nos conduce a concluir que el objeto de protección que se busca en virtud de la función social de la propiedad es diversa de la que se persigue con el establecimiento de las asignaciones forzosas, pues como indica Aurelio Barrio, sobre la base de la Constitución de España:

"Convendría -creemos- distinguir entre función social y familiar, cuyo interés jurídico protegido es bien distinto. Nuestra CE, a diferencias de las ominosas leyes franquistas, atribuye en su art. 33 una función social, pero no familiar, a la herencia. Un silencio que no obsta a discutir después si ha de dispensarse una protección por vía hereditaria a tal grupo social, aunque para ello haya de darse un salto en la topografía constitucional hasta alcanzar el art. 39 CE"31,

regla última que se refiere a la protección social, económica y jurídica de la familia.

Entonces, y solo a partir del análisis de la limitación al derecho de propiedad y alguna de las facultades inherentes al dominio, como es la facultad de disposición a través de la función social de la propiedad, podemos confirmar el evidente conflicto constitucional con el sistema de asignaciones forzosas imperante en nuestra legislación civil, puesto que la propia Constitución establece la reserva legal para limitar la propiedad o alguna de las facultades inherentes al dominio, pero basado en su función social, cuyos rubros tienen por objetivo la protección de intereses

\footnotetext{
${ }^{30}$ Evans (1999), p. 235.

${ }^{31}$ BARRIo (2019), p. 300.
} 
colectivos $^{32}$, aspectos que no comprende la justificación de la limitación sucesoria a través de las asignaciones forzosas, sin perjuicio de lo que diremos a continuación a propósito de la protección y reconocimiento constitucional de la familia.

\section{FAMILIA Y CONSTITUCIÓN}

Ni la Constitución ni el Código Civilhan conceptualizado a la familia, aun cuando se ha indicado por la doctrina que se puede extraer una idea, según lo dispuesto en el art. 815 del Código Civil, el cual señala:

"La familia comprende al cónyuge y los hijos; tanto los que existen al momento de la constitución, como los que sobrevienen después, y esto aun cuando el usuario o el habitador no esté casado, ni haya reconocido hijo alguno a la fecha de la constitución”.

Esta regla está ubicada en el libro II, a propósito del análisis de los derechos reales de uso y de habitación.

De ciertos antecedentes históricos se puede extraer que el legislador otorgaba una protección preferente a los integrantes de la familia fundada en el matrimonio. Ello se manifestaba en el mensaje del Código Civil, tanto respecto del matrimonio en sí como de la preferencia por la protección de los hijos legítimos en desmedro de aquellos que no tenían dicha calidad. En relación con el matrimonio mismo, en esa época solo tenía eficacia el que se celebraba ante la Iglesia católica. Así, el mensaje indicaba:

"Se conserva a la autoridad eclesiástica el derecho de decisión sobre la validez del matrimonio y se reconocen como impedimentos para contraerlos los que han sido declarados tales por la Iglesia Católica. El matrimonio que es válido a los ojos de la Iglesia, lo es también ante la ley civil [...]”.

Y en cuanto a la filiación, se distinguía entre la legítima, la natural y la simplemente ilegítima, indicándose:

"La calidad de hijo legítimo es una de las más importantes que el derecho civil ha creado. ¿Cómo, pues, dejarla a la merced de pruebas testimoniales, tan fáciles de fraguar, si no en la vida de los padres, a lo menos después de sus días?”,

${ }^{32}$ Díez-Picazo (2008), p. 65. 
con lo que, más aún, se reconocía una fuerte limitación a la indagación de la paternidad.

Pero la concepción de la familia es variable y se va adaptando a las nuevas realidades sociales, siendo la propia ley la que le va dando protección a otras formas de familia, estableciéndose nuevos principios ${ }^{33}$. Así, por ejemplo, en materia de filiación se ha avanzado notablemente en la indagación de la paternidad y la maternidad y se ha consagrado la plena igualdad entre todos los hijos o hijas, cualquiera sea su filiación, con la entrada en vigencia de la Ley n. ${ }^{\circ} 19585$ del año 1998. En cuanto a la regulación de las uniones no matrimoniales, la Ley n. ${ }^{\circ} 20830$ de 2015 crea el Acuerdo de Unión Civil, que permite, según su inc. $1 .^{\circ}$ a dos personas, sean de distinto o del mismo sexo "regular los efectos jurídicos derivados de su vida afectiva en común, de carácter estable y permanente" ${ }^{34}$. Y en el Congreso se encuentran en actual discusión diversos proyectos de ley, que quieren extender la posibilidad de que el matrimonio también se pueda celebrar entre personas del mismo sexo ${ }^{35}$. Y esta amplitud del concepto de familia se ha considerado por el legislador en tiempos actuales. Así, la Ley n. ${ }^{\circ} 21150$, que modifica la Ley n. ${ }^{\circ} 20530$ y que crea el Ministerio de Desarrollo Social y Familia, ha incorporado un concepto de familia, definiéndola en su art. $2 .^{\circ}$ como el:

"Núcleo fundamental de la sociedad, compuesto por personas unidas por vínculos afectivos, de parentesco o de pareja, en que existen relaciones de apoyo mutuo, que generalmente comparten un mismo hogar y tienen lazos de protección, cuidado y sustento entre ellos".

Desde el punto de vista constitucional, en diversas legislaciones comparadas revisadas, es posible encontrar textos que dan reconocimiento a la familia, con lo que la doctrina ha comenzado a plantear la existencia de una "constitucionalización del derecho de familia"36. Así, por ejemplo, la Constitución italiana establece en su art. 29:

${ }^{33}$ Lepín (2014), pp. 9-55.

${ }^{34}$ Sobre la familia a la época de entrada en vigencia del Código Civil y su evolución, revísese: Rioseco (1956), pp. 541-560; TAPIA (2005), pp. 102-135; RAMOS (2006), pp. 187199; Del Picó (2011), pp. 31-56; Arancibia y Cornejo (2014), pp. 279-318.

${ }_{35}$ Así, véase el proyecto de ley presentado por mensaje de la presidenta Michelle Bachelet el 5 de septiembre de 2017, Boletín n. ${ }^{\circ} 11422-07$; el proyecto de ley presentado por moción de los diputados: Víctor Torres, Matías Walker, Gabriel Silber, Roberto León, Aldo Cornejo, Vlado Mirosevic, Daniel Farcas, Marco Núñez, Hugo Gutiérrez y Joaquín Godoy el 10 de diciembre de 2014, Boletín No 9778-18 o el proyecto de ley presentado por moción de la diputada Isabel Allende y los diputados Guido Girardi, Ricardo Lagos, Alejandro Navarro y Fulvio Rossi. Boletín n. ${ }^{\circ}$ 7099-07.

${ }^{36}$ LATHROP (2017), pp. 335-337. 
"La República reconoce los derechos de la familia como sociedad natural basada en el matrimonio. El matrimonio se regirá sobre la base de la igualdad moral y jurídica entre ambos cónyuges, con las limitaciones establecidas por la ley como garantía de la unidad familiar",

aun cuando el art. 30 inc. $3 .^{\circ}$ señala:

"La ley garantizará a los hijos nacidos fuera del matrimonio la plena protección jurídica y social de forma compatible con los derechos de los miembros de la familia legítima”.

$\mathrm{El}$ art. 6 n. ${ }^{\circ} 1$ de la Constitución de Alemania indica que "El matrimonio y la familia se encuentran bajo la protección especial del orden estatal", pero el n. ${ }^{\circ} 5$ del mismo artículo señala:

"La legislación deberá asegurar a los hijos extramatrimoniales las mismas condiciones que para los hijos nacidos dentro del matrimonio en lo que respecta a su desarrollo físico y espiritual y a su posición social”.

La Constitución española, entre otras reglas, en su art. 39 n. ${ }^{\circ} 1$ indica: "Los poderes públicos aseguran la protección social, económica y jurídica de la familia".

En Latinoamérica, la Constitución de Brasil, que titula su capítulo VII "De la familia, de los niños, de los adolescentes, de los jóvenes y de las personas mayores", en su art. 226 indica: "La familia es la base de la sociedad y tendrá protección especial del Estado". El art. 5. ${ }^{\circ}$ de la Constitución colombiana, señala:

"El Estado reconoce, sin discriminación alguna, la primacía de los derechos inalienables de la persona y ampara a la familia como institución básica de la sociedad".

La Constitución de Paraguay, declara: "La familia es el fundamento de la sociedad" en su art. 49, pero regula en forma extensa en el capítulo IV a los derechos de familia, en los arts. 49 al 61. Uruguay, en el art. 40 de su Constitución señala: "La familia es la base de nuestra sociedad". El capítulo v de la Constitución de Venezuela, se denomina "De los Derechos Sociales y de las Familias". La Constitución de Bolivia, igualmente dedica una sección completa (la vi) al "derecho de las Familias". O la Constitución de Perú, que en su art. 4 da protección a la familia y al matrimonio, 
pero reconociendo también como familia al concubinato en su art. 5. Y la Constitución de Ecuador, en su art. 67 establece: "Se reconoce la familia en sus diversos tipos" 37 .

En Chile, la Constitución Política de la República, en diversas reglas hace referencia a la familia, como en el art. $1 .^{\circ}$ inc. $2 .^{\circ}$ que establece: "La familia es el núcleo fundamental de la sociedad"; el mismo art. $1^{\circ}$, pero en su inc. 5. ${ }^{\circ}$ indica: "Es deber del Estado resguardar la seguridad nacional, dar protección a la población y a la familia, propender al fortalecimiento de ésta..."; el art. 19 n. ${ }^{\circ} 4 .^{\circ}$, que garantiza "el respeto y protección a la vida privada y a la honra de la persona y su familia, y asimismo, la protección de sus datos personales"; y otras, que, si bien en forma directa no hacen referencia a la familia, sí establecen derechos para los integrantes de ella. Por ejemplo, el art. 19 n. ${ }^{\circ} 10$ inc. $3 .^{\circ}$ establece: "Los padres tienen el derecho preferente y el deber de educar a sus hijos", o el art. $19 \mathrm{n} .{ }^{\circ} 11$ inc. $4 .^{\circ}$ que indica: "Los padres tienen el derecho de escoger el establecimiento de enseñanza para sus hijos". La Constitución de 1925 no hacía declaraciones tan expresas como las señaladas, pero dentro de las garantías constitucionales, reconocía en su art. $10 \mathrm{n} .^{\circ} 14$ :

"La protección al trabajo, a la industria, y a las obras de previsión social, especialmente en cuanto se refieren a la habitación sana y a las condiciones económicas de la vida, en forma de proporcionar a cada habitante un mínimo de bienestar, adecuado a la satisfacción de sus necesidades personales y a las de su familia" 38 .

Pero ninguna de estas reglas hace referencia al tipo de familia que reconoce la actual Constitución ${ }^{39}$, a diferencia de lo que observamos en ciertas experiencias comparadas, en la cual algunas Constituciones dan preferencia en la protección a la familia que emana del matrimonio y, en otras, en las que la tutela alcanza a toda clase de familia, incluyendo las no matrimoniales. Y ello ha sido objeto de cierta discusión por parte de la doctrina, existiendo argumentos para sostener que la familia protegida en la actual Constitución es aquella que proviene del matrimonio ${ }^{40}$, como también la de aquellos que indican que la protección constitucional alcanza a otras familias que no necesariamente provienen del matrimonio ${ }^{41}$.

\footnotetext{
${ }^{37}$ Sobre la protección constitucional de la familia en Latinoamérica, véase DE LA FuENTE (2012), pp. 60-76.

${ }^{38}$ Sobre las fuentes históricas de las diversas normas relativas al concepto de familia en la Constitución de 1980, véase Sото (1994), pp. 217-225.

${ }^{39}$ Sobre el concepto de familia en la Constitución véase García (2009), pp. 1-248.

${ }^{40}$ Véase, por ejemplo, Corral (1994), pp. 27-30.

${ }^{41}$ Véase, por ejemplo, Figueroa (1995), pp. 70-72.
} 
Consideramos que hoy la discusión está zanjada, optando por la segunda alternativa. Como indica René Ramos:

"Cualquier duda que pudiera haber existido sobre el tema ha quedado definitivamente disipada con la dictación de la Ley $\mathrm{N}^{\circ}$ 19.947, que estableció el divorcio en Chile. El artículo $1^{\circ}$ de esta ley expresa que 'La familia es el núcleo fundamental de la sociedad. El matrimonio es la base principal de la familia'. El hecho de que la disposición diga que 'el matrimonio es la base principal de la familia' demuestra que puede existir una familia que no se funda en el matrimonio, la que también debe gozar de la protección constitucional" 42 .

En el mismo sentido Javier Barrientos ${ }^{43}$.

\section{LA PROTECCIÓN CONSTITUCIONAL DE LA FAMILIA COMO LÍMITE A LA FACULTAD DE DISPOSICIÓN POR CAUSA DE MUERTE}

Sobre la base del reconocimiento constitucional de la familia, se podría justificar la existencia de las asignaciones forzosas como límite a la facultad del causante para disponer de sus bienes por causa de muerte a través del testamento, al erigirse la familia como núcleo fundamental de la sociedad. Ello ya lo ha señalado Hernán Corral, al sostener:

"Las asignaciones forzosas, en cuanto no suprimen completamente ese derecho sino que lo restringen sobre la base de un valor constitucional como el de la familia, deben ser consideradas justificadas" ${ }^{\prime 4}$.

Pero, por su parte, existen varios tratados internacionales sobre derechos humanos ratificados por Chile y que se encuentran vigentes que confirman la necesidad de un reconocimiento y protección de la familia y que deben ser respetados a la luz de la nueva Constitución, como el Pacto Internacional de Derechos Civiles y Políticos, que en su art. 23 n. ${ }^{\circ} 1$ señala: "La familia es el elemento natural y fundamental de la sociedad y tiene derecho a la protección de la sociedad y del Estado"; la Convención Americana sobre Derechos Humanos que indica en su art. 17 n. ${ }^{\circ} 1$ que

\footnotetext{
${ }^{42}$ Ramos (2007), pp. 12-13.

${ }^{43}$ Barrientos (2011), p. 32.

${ }^{44}$ Corral (2005), p. 167.
} 
"la familia es el elemento natural y fundamental de la sociedad y debe ser protegida por la sociedad y el Estado" o el art. 16 n. ${ }^{\circ} 3$ de la Declaración Universal de los Derechos Humanos que establece: "La familia es el elemento natural y fundamental de la sociedad y tiene derecho a la protección de la sociedad y del Estado" 45.

Pero lo que estas normas exigen es la "protección de la familia" y por ello que no es tan claro que, a partir de esa específica protección, las asignaciones forzosas se encuentren justificadas como un límite a la facultad de disposición del causante. Por ello, es legítimo preguntarse, ¿̇requieren protección sucesoria o hereditaria todos los integrantes de la familia, incluso aquellos que tienen un patrimonio cuantioso y que pueden desenvolverse por sí mismos, sin necesidad de ninguna otra ayuda?

Se ha dado justificación de las asignaciones forzosas a través de una serie de argumentos de carácter familiar, como la copropiedad familiar, el fideicomiso tácito entre los integrantes de la familia, la mantención de la integridad del patrimonio familiar y la solidaridad generacional, entre otras razones ${ }^{46}$. Pero también se ha criticado la mantención de ellas, fundamentalmente porque hoy ya no cumplen la función protectora que tenían al tiempo de su establecimiento. Ramón Domínguez Águila se pregunta:

"¿Qué rol cumple, por ejemplo, la legítima, si los hijos son ya personas muy mayores con una vida formada y con un destino que ellos mismos ya se han trazado y en el que poca influencia podría tener la adquisición de algunos bienes del causante? Desde luego, ya no es necesaria para la mantención de esos hijos, porque ninguna obligación patrimonial ha de tener el padre frente a ellos" ${ }^{\prime 7}$.

O como señala Antoni Vaquer:

“¿ ¿No es un reflejo del más recalcitrante individualismo que el legitimario pueda esperar tranquilamente al fallecimiento del causante, sin preocuparse para nada de sus necesidades o transmitirle un mínimo de afecto en sus últimos días, para recibir una parte de la herencia? ¿De qué protección de la familia estamos hablando, si se recibe una parte de la herencia incluso si no se contribuye en nada al bienestar de sus miembros?" ${ }^{48}$.

\footnotetext{
${ }^{45}$ Véase a Veloso (1998), pp. 35-56.

${ }^{46}$ Elorriaga (2019), pp. 85-88.

${ }^{47}$ Domínguez (2007), p. 492.

${ }^{48}$ VAQUer (2018), p. 61.
} 
En Chile, la esperanza de vida era de 23,6 años para las mujeres y 23,5 años para los varones en el año 1900. Entre los años 2015 al 2020, esta esperanza se ha extendido a 82,1 en las mujeres y 77,3 años en los varones, según los datos del Instituto Nacional de Estadísticas ${ }^{49}$. Por ello, como indica Nathalie Walker:

"Podemos calcular que los herederos de esas personas tendrán alrededor de cincuenta años al producirse la muerte de aquellos. De ello resulta que, si el asignatario tendrá esa edad al momento de abrirse la sucesión, el torcer por la vía legal la genuina voluntad del testador, a través de las asignaciones forzosas constituye un exceso intolerable" ${ }^{50}$.

En ese sentido, somos de la opinión que debe existir armonía entre la protección constitucional de la familia y la libertad de disposición del testador, que también se consagra a dicho nivel, a través de la garantía constitucional del derecho de propiedad, que puede ser limitado, pero basado en la función social que, como hemos señalado, no encuentra justificación en las asignaciones forzosas. Por eso, sostenemos que es necesario distinguir entre el reconocimiento constitucional de la familia, de la protección constitucional de la familia.

La familia como tal, sea matrimonial o no matrimonial debe ser reconocida, incluso, constitucionalmente, como base fundamental de la sociedad, pero en cuanto a la protección de sus integrantes, debe alcanzar a aquellos que no pueden valerse por sí mismos, como el caso de los menores. Y, si bien, ellos en la actualidad gozan de diversos derechos, entre ellos el derecho de alimentos, somos de la idea de que las asignaciones forzosas deben alejarse de los principios de la copropiedad familiar y de la solidaridad intergeneracional. Esto, porque como fundamento ya no se justifican, avanzando precisamente al establecimiento de asignaciones forzosas con fundamento alimenticio, lo que no es una novedad en el sistema jurídico comparado, como el Código Civil de Luisiana, que ha establecido un límite de edad (veintitrés años) para que los hijos tengan derechos hereditarios en su calidad de legitimarios ${ }^{51}$.

Esta protección de los menores tendría también justificación constitucional, aun con las actuales normas. De hecho, el art. 19 n. ${ }^{\circ} 10$, cuando consagra el derecho a la educación indica expresamente en su inc. 3. ${ }^{\circ}$ :

${ }^{49}$ Instituto Nacional de Estadísticas (2019).

${ }^{50}$ WaLKer (2019), pp. 572-573.

${ }^{51}$ Sobre los derechos hereditarios de los legitimarios menores, véase BARRÍA (2014), pp. 245-249. 
"Los padres tienen el derecho preferente y el deber de educar a sus hijos" e, incluso, en el mismo art. 19, pero en su n. ${ }^{\circ} 11$ inc. $4 .^{\circ}$ se indica: "Los padres tienen el derecho de escoger el establecimiento de enseñanza para sus hijos", lo que trae como consecuencia, el financiamiento del mismo. Y si es un deber de los padres el de educar a sus hijos, ello es justificación del deber de alimentos que la ley civil ha establecido y que se desprende de los arts. 321 y 322 del Código Civil, además de lo dispuesto en la Ley n. ${ }^{\circ} 14908$, sobre abandono de familia y pago de pensiones alimenticias.

Pero además la protección de las asignaciones forzosas para los hijos menores se justifica, también, de la lectura de ciertos tratados internacionales sobre derechos humanos que se encuentran ratificados por Chile y que se encuentran vigentes, y que deben respetarse por la nueva Constitución. Por ejemplo, el Pacto Internacional de Derechos Civiles y Políticos señala en su art. $24 \mathrm{n} .{ }^{\circ} 1$ :

"Todo niño tiene derecho, sin discriminación alguna por motivos de raza, color, sexo, idioma, religión, origen nacional o social, posición económica o nacimiento, a las medidas de protección que su condición de menor requiere, tanto por parte de su familia como de la sociedad y del Estado";

el art. 19 de la Convención Americana de Derechos Humanos, indica:

"Todo niño tiene derecho a las medidas de protección que su condición de menor requieren por parte de su familia, de la sociedad y del Estado";

la Convención de los Derechos del Niño, que en el art. 18 n. ${ }^{\circ} 1$ establece:

“Los Estados Partes pondrán el máximo empeño en garantizar el reconocimiento del principio de que ambos padres tienen obligaciones comunes en lo que respecta a la crianza y el desarrollo del niño. Incumbirá a los padres o, en su caso, a los representantes legales la responsabilidad primordial de la crianza y el desarrollo del niño. Su preocupación fundamental será el interés superior del niño",

y también el art. 27 n. ${ }^{\circ} 2$ consagra:

"A los padres u otras personas encargadas del niño les incumbe la responsabilidad primordial de proporcionar, dentro de sus posibilidades y medios económicos, las condiciones de vida que sean necesarias para el desarrollo del niño". 
VI. LA PROTECCIÓN CONSTITUCIONAL DE LAS PERSONAS DISCAPACITADAS COMO LÍMITE A LA FACULTAD DE DISPOSICIÓN POR CAUSA DE MUERTE

Como hemos indicado, la naturaleza de las asignaciones forzosas debe avanzar desde una de carácter hereditaria a una de carácter alimenticia $\mathrm{y}$, de esa forma, encuadrarse dentro de la protección constitucional de la familia. Por consiguiente, las asignaciones forzosas, especialmente la legítima y la mejora solo debieran estar reservadas para los integrantes de la familia que lo requieran, con lo cual se podría ampliar la libertad de disposición del causante, equilibrando esta citada libertad con la protección de la familia. Por ello, no solo los hijos menores requieren de la protección sucesoria a través de las asignaciones forzosas, sino que, también, se requiere tutelar con este mecanismo a aquellos hijos que, siendo mayores, sufran alguna discapacidad, protección que se debe extender por toda su vida de ser necesario, manifestándose la solidaridad intergeneracional.

La actual Constitución no hace mención alguna a derechos y protección de las personas discapacitadas. Sin embargo, la reforma constitucional que convoca a la elaboración de la nueva Constitución, estableció un mecanismo especial de participación en la Convención Constitucional de las personas discapacitadas. Así, la disposición cuadragésima séptima transitoria de la Constitución señala:

"De la participación de las personas con discapacidad en la elección de Convencionales Constituyentes. Con la finalidad de resguardar y promover la participación de las personas con discapacidad en las elecciones de los Convencionales Constituyentes para redactar la nueva Constitución Política, de la totalidad de las declaraciones de candidaturas de las listas conformadas por un solo partido político o pactos electorales de partidos políticos, se establecerá un porcentaje mínimo del cinco por ciento del total respectivo de candidaturas para personas con discapacidad".

Sin perjuicio de lo anterior, en Chile se han dictado algunas leyes que tienen por objetivo proteger a las personas con discapacidad ${ }^{52}$, siendo la

${ }^{52}$ Dentro de ellas mencionaremos, entre otras: la Ley n. ${ }^{\circ}$ 19284, de 14 de enero de 1994, que establece normas para la plena integración social de personas con discapacidad; la Ley n. ${ }^{\circ}$ 20146, de 9 de enero de 2007, que establece reglas especiales para la apelación en causas relativas a la discapacidad; la Ley n. ${ }^{\circ} 20183$, de 8 de junio de 2007, que modifica la Ley n. ${ }^{\circ} 18700$, orgánica constitucional sobre votaciones populares y escrutinios, con el objeto de reconocer el derecho a la asistencia en el acto de votar para las personas con discapacidad; la Ley n. ${ }^{\circ}$ 20978, de 16 de diciembre de 2016, que reconoce el deporte adaptado y paralímpico; la Ley n. ${ }^{\circ} 21015$, del 15 de junio de 2017, que incentiva la inclusión 
más relevante la Ley n. ${ }^{\circ} 20422$ de 10 de febrero de 2010 que establece normas sobre igualdad de oportunidades e inclusión social de personas con discapacidad, y que según su art. $1 .^{\circ}$ tiene por objetivo:
"Asegurar el derecho a la igualdad de oportunidades de las personas con discapacidad, con el fin de obtener su plena inclusión social, asegurando el disfrute de sus derechos y eliminando cualquier forma de discriminación fundada en la discapacidad".

Si bien no existe ninguna regla que le asigne o garantice derechos hereditarios a las personas con discapacidad, es necesario tener presente lo que dispone el art. 9, que se aplica a las personas con discapacidad en situación de especial vulnerabilidad y que señala:

"El Estado adoptará las medidas necesarias para asegurar a las mujeres con discapacidad y a las personas con discapacidad mental, sea por causa psíquica o intelectual, el pleno goce de sus derechos en condiciones de igualdad con las demás, en especial lo referente a su dignidad, el derecho a constituir y ser parte de una familia, su sexualidad y salud reproductiva. Asimismo, el Estado adoptará las acciones conducentes a asegurar a los niños con discapacidad el pleno goce y ejercicio de sus derechos, en especial el respeto a su dignidad, el derecho a ser parte de una familia y a mantener su fertilidad, en condiciones de igualdad con las demás personas. De igual modo, el Estado adoptará las medidas necesarias para evitar las situaciones de violencia, abuso y discriminación de que puedan ser víctimas las mujeres y niños con discapacidad y las personas con discapacidad mental, en razón de su condición”.

Así, es deber del Estado asegurar que las personas con discapacidad tengan derecho a constituir y ser parte de una familia, lo que implica la obligación de su protección como integrante de ella.

Y, además, se puede extraer como un principio, que el legislador ha querido otorgar prestaciones alimenticias para personas con discapacidad por toda su vida de ser necesario. Por esta razón, el art. 332 del Código Civil establece:

de personas con discapacidad al mundo laboral; la Ley n. ${ }^{\circ}$ 21168, de 27 de julio de 2019, que modifica la Ley n. ${ }^{\circ} 20584$, a fin de crear el derecho a la atención preferente y la Ley n. ${ }^{\circ} 21303$, de 22 de enero de 2021, que modifica la Ley n. ${ }^{\circ}$ 20422, que establece normas sobre igualdad de oportunidades e inclusión social de personas con discapacidad, para promover el uso de la lengua de señas. 
"Los alimentos que se deben por ley se entienden concedidos para toda la vida del alimentario, continuando las circunstancias que legitimaron la demanda. Con todo, los alimentos concedidos a los descendientes y a los hermanos se devengarán hasta que cumplan veintiún años, salvo que estén estudiando una profesión u oficio, caso en el cual cesarán a los veintiocho años; que les afecte una incapacidad física o mental que les impida subsistir por sí mismos, o que, por circunstancias calificadas, el juez los considere indispensables para su subsistencia”.

Por esta razón, frente a demandas de cese de alimentos presentadas por parte del alimentante en caso de que el alimentario haya alcanzado la edad legal establecida en dicha norma, en caso que ellos tengan alguna discapacidad, el tribunal las ha rechazado, fundado precisamente en esa calidad del alimentario, prolongando para él su derecho de alimentos. Así se ha fallado que:

"Como se puede apreciar, el recurrente padece de una discapacidad caracterizada como Trastorno Generalizado del Desarrollo del tipo Asperger, síndrome que lo torna en una persona dependiente de otros durante toda su vida, como lo ponen de manifiesto los informes psiquiátrico y psicológico referidos precedentemente, que en este caso se manifiesta en una real necesidad de contar con el apoyo continuo de su madre, tanto desde un punto de vista emocional como económico, pues por su condición y fobia social no está capacitado para desempeñar su trabajo".

Y en otro considerando se señalaba:

"Que, en consecuencia cobra aplicación en la especie la citada norma del artículo 332 del Código Civil, en aquella parte que establece que si bien los alimentos concedidos a favor de los descendientes se devengarán hasta que cumplan veintiún años, o hasta los veintiocho años si están estudiando una profesión u oficio, ello no acontecerá, si a tales descendientes les afectare una incapacidad física o mental que les impida subsistir por si mismos, cuyo es el caso" ${ }^{53}$.

En el derecho comparado existen diversas experiencias en que a través de la ley se les confieren derechos hereditarios a las personas con discapacidad. Se pueden dar como ejemplos aquellos sistemas del Common

${ }^{53}$ P. R. con P. S. (2015). En el mismo sentido: Z. A. con Z. Z. (2016); C. B. con G. M. (2019). 
Law, que, partiendo de un principio de libertad de testar, han establecido limitaciones de naturaleza alimenticia a través de las denominadas family provisions ${ }^{54}$. Pero hay otros sistemas que, siguiendo limitaciones a la libertad de testar a través de la legítima, han avanzado otorgando derechos hereditarios a personas con discapacidad. Por ejemplo, el Código Civil de Cuba reserva una parte de los bienes del causante a los llamados "herederos especialmente protegidos", por lo que, en caso de concurrir, limitan la libertad de disposición del causante. Así, el art. 492.1 indica: "La libertad de testar se limita a la mitad de la herencia cuando existen herederos especialmente protegidos". Y tienen la calidad de herederos especialmente protegidos los hijos o los descendientes del causante, en caso de premuerto aquellos; el cónyuge sobreviviente y los ascendientes, siempre que no estén aptos para el trabajo y que dependan económicamente del causante ${ }^{55}$.

También es necesario citar el referido Código de Luisiana, que actualmente establece como excepción al límite de veintitrés años para reservar la legítima, a los descendientes del causante, siempre y cuando tengan una incapacidad mental o una enfermedad física o que permanentemente estén al cuidado de personas. El Código Civil y Comercial de la Nación Argentina ha establecido una mejora a favor del heredero que padezca de alguna discapacidad, en los siguientes términos:

"El causante puede disponer, por el medio que estime conveniente, incluso mediante un fideicomiso, además de la porción disponible, de un tercio de las porciones legítimas para aplicarlas como mejora estricta a descendientes o ascendientes con discapacidad. A estos efectos, se considera persona con discapacidad, a toda persona que padece una alteración funcional permanente o prolongada, física o mental, que en relación a su edad y medio social implica desventajas considerables para su integración familiar, social, educacional o laboral" ${ }^{\prime 6}$.

Y el Código Civil español contempla diversas reglas que le otorgan protección a las personas con discapacidad, fruto de una modificación legal del año $2003^{57}$. Por ejemplo, el art. 808 señala:

${ }^{54}$ Sobre estas limitaciones en el Common Law, véase MARAÑón (2019), pp. 621-642.

${ }^{55}$ Sobre los herederos especialmente protegidos en el derecho cubano, véase PéREz (2010), pp. 357-368.

${ }^{56}$ Para el derecho argentino véase Ferrer (2019), pp. 119-125; Medina (2019), pp. 238 -

241; Córdoba (2019), pp. 359-367.

${ }^{57}$ Véase Escribano (2019), pp. 395-411. 
"Constituyen la legítima de los hijos y descendientes las dos terceras partes del haber hereditario del padre y de la madre. Sin embargo, podrán éstos disponer de una parte de las dos que forman la legítima, para aplicarla como mejora a sus hijos o descendientes. Cuando alguno de los hijos o descendientes haya sido judicialmente incapacitado, el testador podrá establecer una sustitución fideicomisaria sobre el tercio de legítima estricta, siendo fiduciarios los hijos o descendientes judicialmente incapacitados y fideicomisarios los coherederos forzosos. La tercera parte será de libre disposición".

O el art. 822 que indica:

"La donación o legado de un derecho de habitación sobre la vivienda habitual que su titular haga a favor de un legitimario persona con discapacidad, no se computará para el cálculo de las legítimas si en el momento del fallecimiento ambos estuvieren conviviendo en ella",

todas medidas y derechos hereditarios para dar protección a personas con discapacidad.

Se puede apreciar, entonces, que las legislaciones comparadas, cuando realizan modificaciones en materias vinculadas a la sucesión por causa de muerte, le otorgan una mayor protección a las personas que se encuentran en estado de discapacidad, lo que nos permite afirmar la tendencia que la legítima debe avanzar hacia una de naturaleza asistencial o alimenticia y no hereditaria. Si bien, lo anterior pudiera lograrse a través de la asignación forzosa del art. $1167 \mathrm{n}^{\circ}$ 1, esto es, "los alimentos que se deben por ley a ciertas personas", consideramos que es insuficiente, de partida porque es de escasa aplicación práctica, no siendo en general demandados cuando el causante ha fallecido, $Y$ además porque la ley las considera una baja general de la herencia en el art. 959 n. ${ }^{\circ} 4$, muy pocas veces también aplicado. Por ello, el efecto protector se debe plasmar en la legítima y la mejora, asignaciones forzosas por excelencia y que requieren de una revisión.

En materia constitucional, las experiencias comparadas latinoamericanas demuestran que en el último tiempo, diversas Constituciones han consagrado el papel protector de las personas con discapacidad. Por ejemplo, el art. 75 n. ${ }^{\circ} 23$ de la Constitución de Argentina indica como atribuciones del Congreso el:

"Legislar y promover medidas de acción positiva que garanticen la igualdad real de oportunidades y de trato, y el pleno goce y ejer- 
cicio de los derechos reconocidos por esta Constitución y por los tratados internacionales vigentes sobre derechos humanos, en particular respecto de los niños, las mujeres, los ancianos y las personas con discapacidad".

La Constitución de Perú, en su art. 7 establece el derecho a la salud y la protección al discapacitado, indicando:

"Todos tienen derecho a la protección de su salud, la del medio familiar y la de la comunidad, así como el deber de contribuir a su promoción y defensa. La persona incapacitada para velar por sí misma a causa de una deficiencia física o mental tiene derecho al respeto de su dignidad y a un régimen legal de protección, atención, readaptación y seguridad”.

O la Constitución de Paraguay, que contiene diversas reglas de tutela de personas discapacitadas, destacando el art. 58 que se refiere a los "derechos de las personas excepcionales", al señalar:

"Se garantizará a las personas excepcionales la atención de su salud, 170 de su educación, de su recreación y de su formación profesional para una plena integración social. El Estado organizará una política de prevención, tratamiento, rehabilitación e integración de los discapacitados físicos, psíquicos y sensoriales, a quienes prestará el cuidado especializado que requieran. Se les reconocerá el disfrute de los derechos que esta Constitución otorga a todos los habitantes de la República, en igualdad de oportunidades, a fin de compensar sus desventajas".

Y el art. 81 de la Constitución de Venezuela reconoce:

"Toda persona con discapacidad o necesidades especiales tiene derecho al ejercicio pleno y autónomo de sus capacidades y a su integración familiar y comunitaria. El Estado, con la participación solidaria de las familias y la sociedad, le garantizará el respeto a su dignidad humana, la equiparación de oportunidades, condiciones laborales satisfactorias, y promoverá su formación, capacitación y acceso al empleo acorde con sus condiciones, de conformidad con la ley. Se les reconoce a las personas sordas o mudas el derecho a expresarse y comunicarse a través de la lengua de señas venezolana". 
Pero existen otras Constituciones que destinan una parte importante de ella a la protección de las personas discapacitadas como, por ejemplo, la Constitución de Ecuador, que dedica su sección sexta a las "personas con discapacidad", declarando fundamentalmente en el art. 47:

"El Estado garantizará políticas de prevención de las discapacidades y, de manera conjunta con la sociedad y la familia, procurará la equiparación de oportunidades para las personas con discapacidad y su integración social”.

Y también la Constitución de Bolivia, que contiene una parte especial, la sección VIII destinada a los "derechos de las personas con discapacidad", destacando el art. 71 n. ${ }^{\circ}$, que establece:

"El Estado adoptará medidas de acción positiva para promover la efectiva integración de las personas con discapacidad en el ámbito productivo, económico, político, social y cultural, sin discriminación alguna",

aunque de igual manera se reconocen los derechos de las personas discapacitadas en el seno de la familia, al señalar en el art. $64 \mathrm{n}^{\circ}{ }^{\circ}$ :

"Los cónyuges o convivientes tienen el deber de atender, en igualdad de condiciones y mediante el esfuerzo común, el mantenimiento y responsabilidad del hogar, la educación y formación integral de las hijas e hijos mientras sean menores o tengan alguna discapacidad".

Además, en Chile se han firmado tratados internacionales relacionadas con la protección de las personas discapacitadas ${ }^{58}$. Una de ellas es la Convención Interamericana para la Eliminación de todas las Formas de Discriminación contra las Personas con Discapacidad, publicada en el Diario Oficial el 20 de junio de 2002. Pero otro importante tratado es la Convención de las Naciones Unidas sobre los Derechos de las Personas con Discapacidad y su Protocolo Facultativo, publicado en el Diario Oficial el 17 de septiembre de 2008, que contiene una interesante regla en el art. 28 n. ${ }^{\circ} 1$, que señala:

${ }^{58}$ Una mirada a los derechos de las personas con discapacidad, con especial enfoque desde el derecho internacional de los derechos humanos en: MARSHALL (2020), pp. 45-81; Gauché (2019), pp. 103-129; Finsterbusch (2016), pp. 227-252. 
"Los Estados Partes reconocen el derecho de las personas con discapacidad a un nivel de vida adecuado para ellas y sus familias, lo cual incluye alimentación, vestido y vivienda adecuados, y a la mejora continua de sus condiciones de vida, y adoptarán las medidas pertinentes para salvaguardar y promover el ejercicio de este derecho sin discriminación por motivos de discapacidad".

Por lo tanto, en este tratado se establece como principio el deber de dar protección a las personas con discapacidad, asegurando alimentación, vestimenta y vivienda, para el desarrollo y sus condiciones de vida, lo que es coherente con el establecimiento de derechos sucesorios a su favor, con carácter alimenticio o asistencial.

\section{LA PROTECCIÓN CONSTITUCIONAL SUCESORIA DE MENORES Y DISCAPACITADOS FRENTE AL PRINCIPIO DE IGUALDAD ANTE LA LEY}

Uno de los principios que ha inspirado el sistema sucesorio chileno es el de igualdad, el cual se manifiesta en diversos aspectos, lo cual, además, se profundiza con la entrada en vigencia de la Ley n. ${ }^{\circ} 19585$, que estableció la igualdad de derechos de todos los hijos cualquiera sea su filiación. Así, por ejemplo, en la sucesión intestada, en el primer orden de sucesión concurren los hijos, personalmente o representados, que llevan iguales derechos entre ellos, según el art. 988 inc. $4 .^{\circ}$. Y por su parte, el art. 1183 establece: "Los legitimarios concurren y son excluidos y representados según el orden y reglas de la sucesión intestada", por lo que entonces, cuando los hijos personalmente o representados por su descendencia concurren como legitimarios, ellos llevan iguales partes. Y esa igualdad también se configura en el reparto del pasivo hereditario. Los legitimarios son herederos, según el art. 1181 y en esa calidad son continuadores de la persona del causante y lo suceden en todos sus derechos y obligaciones transmisibles, de acuerdo con lo señalado en los arts. 951 y 1097 del Código Civil, por lo que responden por las deudas del causante y, según se extrae del art. 1354 "las deudas hereditarias se dividen entre los herederos a prorrata de sus cuotas", confirmando este principio de igualdad ${ }^{59}$.

Y en ese sentido es posible preguntarse si establecer formas preferentes de protección sucesoria a favor de personas discapacitadas o de hijos o descendientes menores por sobre aquellos que no tengan esa calidad,

${ }^{59}$ Sobre el principio de igualdad en el derecho sucesorio, véase: Peñailillo (1968), pp. 59-109; Peñallillo (1969), pp. 45-56; Domínguez (2006), pp. 222-223; Domínguez y Domínguez (2011), pp. 114-121; SALAH (2019), pp. 535-563. 
¿atenta contra el principio de igualdad ante la ley y que se consagra en la Constitución? En efecto, el art. 19 n. ${ }^{\circ} 2$ de la Carta Fundamental asegura a todas las personas:

"La igualdad ante la ley. En Chile no hay personas ni grupo privilegiados. En Chile no hay esclavos y el que pise su territorio queda libre. Hombres y mujeres son iguales ante la ley. Ni la ley ni autoridad alguna podrán establecer diferencias arbitrarias",

principio contemplado en las diferentes Constituciones estudiadas y en los diversos tratados internacionales ratificados por Chile y que se encuentran vigentes.

Pero el alcance de este principio también merece de un análisis particular, máxime si la protección sucesoria pretendida privilegia a personas menores de edad y discapacitados por sobre a aquellas que no tienen esta calidad. Varias de las Constituciones y de los tratados internacionales revisados establecen que, en el caso de personas discapacitadas, los Estados pueden tomar medidas de acción positivas, para garantizar los derechos de estas personas, con el objetivo de, en lo posible, equipararlas con los derechos de las personas que no padecen de esta situación.

Lo que se prohíbe por la Constitución es hacer diferencias arbitrarias en el otorgamiento de derechos, lo que en palabras de Iván Díaz alude:

"A un actuar irracional, injustificado, inmotivado o por mero capricho, según han explicado la jurisprudencia y la doctrina. En consecuencia, lo prohibido son las diferencias irracionales, inmotivadas, injustificadas o por mero capricho. Por el contrario, una diferencia racional, justificada, motivada o no caprichosa está ordenada o al menos permitida" ${ }^{\prime 60}$.

O como señala Humberto Nogueira:

"La igualdad ante la ley obliga a que esta sea aplicada de modo igual a todos aquellos que se encuentran en la misma situación, sin que el operador pueda establecer diferencia alguna en razón de las personas, o de circunstancias que no sean precisamente las presentes en las normas" ${ }^{1}$.

$\mathrm{Al}$ contrario, entonces, se pueden explicar diferencias entre personas que no se encuentren en la misma situación y por eso se justifica una pro-

${ }^{60}$ DíAz (2012), pp. 63-64.

${ }^{61}$ Nogueira (2006), p. 69. 
tección sucesoria de carácter alimenticia o asistencial a favor de personas menores de edad o discapacitadas, lo cual se puede extraer de la propia Constitución o de los tratados internacionales sobre derechos humanos ratificados por Chile y que se encuentren vigentes. Por ejemplo, el art. 1 inc. 4 de la Constitución establece:

"El Estado está al servicio de la persona humana y su finalidad es promover el bien común, para lo cual debe contribuir a crear las condiciones sociales que permitan a todos y cada uno de los integrantes de la comunidad nacional su mayor realización espiritual y material posible, con pleno respeto a los derechos y garantías que esta Constitución establece”.

Y como señala Humberto Nogueira:

"La adopción de acciones positivas o de discriminación inversa, son constitucionalmente legítimas para alcanzar niveles de equidad o situar en situación justa a grupos sociales tradicionalmente discriminados negativamente, todo lo cual requiere que la norma legislativa sea idónea para lograr el objetivo de eliminar la inequidad, cuya situación fáctica debe estar objetivamente establecida, siendo dicha normativa transitoria, solo mientras permanezca la desigualdad inequitativa. Ello supone, en algunos casos, consagrar una protección especial a las personas o grupos que, por sus condiciones físicas, mentales, culturales o económicas se encuentran en situación de discriminación o que agravan la situación de debilidad de otros individuos o grupos" ${ }^{\prime 2}$.

Y esta concepción por la cual se pueden determinar acciones positivas o de discriminación inversa ha sido, incluso, reconocida por algunas de las sentencias del Tribunal Constitucional, que ha señalado:

"La igualdad ante la ley consiste en que las normas jurídicas deben ser iguales para todas las personas que se encuentren en las mismas circunstancias y, consecuencialmente, diversas para aquellas que se encuentren en situaciones diferentes" ${ }^{\prime 3}$.

${ }^{62}$ Nogueira (2006), pp. 95-96.

${ }^{63}$ Sobre este punto: Control de constitucionalidad al proyecto de Ley sobre Votaciones Populares y Escrutinios (1988), cons. 72. ${ }^{\circ}$. En el mismo sentido, Requerimiento de inconstitucionalidad al proyecto de ley sobre reajuste extraordinario de $10 \%$ de las pensiones (1995), cons. $17^{\circ}$; Requerimiento de inconstitucionalidad del Colegio de Abogados al art. 595 COT(2009), cons. $48 .^{\circ}$; Requerimiento de inaplicabilidad de J. C. y otros al art. 10, letra h, de la Ley n. 20285 (2011), cons. $48 .^{\circ}$. 


\section{Conclusiones}

Se reconoce una expresa vinculación entre la familia y el derecho de propiedad, que se manifiesta fundamentalmente en el sistema sucesorio chileno, en el cual la libertad de disposición del causante se encuentra limitada por las asignaciones forzosas que pertenecen a algunos integrantes de la familia.

Además, se puede sostener que aun cuando la Constitución no reconoce de modo expreso como garantía fundamental al derecho de herencia, se puede llegar a esa conclusión en virtud de la teoría de la propietarización de los derechos, que alcanza a los derechos reales, dentro de los cuales se encuentra el derecho real de herencia.

El derecho de propiedad y sus facultades inherentes se pueden restringir o limitar, siempre que deriven de la llamada "función social de la propiedad", concluyendo que las asignaciones forzosas no se encuentran incorporadas dentro de este concepto, pues no se ve que quede asociado a ninguno de los factores que constitucionalmente forman parte de esta función social.

La familia es reconocida constitucionalmente, cualquiera sea su naturaleza, lo que también queda establecido de la lectura de diversas constituciones comparadas y también de tratados internacionales sobre derechos humanos ratificados por Chile y que se encuentran vigentes. Sin embargo, la protección constitucional de la familia debe quedar reducida solo para quienes lo necesiten, como los descendientes menores y las personas discapacitadas que dependan económicamente del causante. Y es basado en la tutela de estas personas, que debería limitarse la facultad de disposición del causante y no sobre la base de la función social de la propiedad.

Así entonces, la limitación sucesoria de las asignaciones forzosas avanzaría desde una de carácter hereditario a una de carácter alimenticia, sin que con ello se afecte el principio de igualdad ante la ley, garantía también constitucional, estableciéndose acciones positivas o de discriminación inversa, como la proteger desde el punto de vista sucesorio a través de la legítima y la mejora a descendientes menores del causante y a los que, siendo mayores, se encuentren en estado de discapacidad, con preferencia de los demás integrantes de la familia, que, a su vez, también podrían ser beneficiados hereditariamente con cargo a la parte de libre disposición, si así lo decide el testador.

\section{BibLIOGRAFÍA CITADA}

Arancibia Obrador, María José y Pablo Cornejo Aguilera (2014). "El derecho de familia en Chile. Evolución y nuevos desafíos”. Ius et Praxis, año 20, n. ${ }^{\circ}$ 1. Talca. 
Barría Paredes, Manuel (2014). Asignaciones forzosas y libertad de testar. Santiago: Legal Publishing/Thomson Reuters.

Barrientos Grandón, Javier (2011). Derecho de las personas. El derecho matrimonial. Santiago: Abeledo Perrot/ Thomson Reuters.

Barrio Gallardo, Aurelio (2019). "El ocaso de las legítimas largas", en Francisco Capilla Roncero; Manuel Espejo Lerdo de Tejada y Francisco José Aranguren Urriza (dirs.). Las legítimas y la libertad de testar. Perfiles críticos y comparados. Navarra: Thomson Reuters/Aranzadi.

Benzina, Samy (2020). "Les enjeux constitutionnels de la réserve héréditaire", en Cécile Pérès et Philippe Potentier (coords.). La réserve héréditaire. Paris: Éditions Panthéon-Assas.

Brantt Zumarán, María Graciela y Álvaro Vidal Olivares (2017). "La afectación de los derechos y acciones como bienes familiares y alcance del art. $146 \mathrm{del}$ Código Civil". Revista de Derecho Universidad Austral de Chile, vol. 30, n. ${ }^{\circ} 1$. Valdivia.

Carbonnier, Jean (2001). Flexible Droit. Pour une sociologie du droit sans rigueur. $10^{\circ}$ édition. Paris: LGDJ.

Cordero Quinzacara, Eduardo (2008). "De la propiedad a las propiedades. La evolución de la concepción liberal de la propiedad". Revista de Derecho Pontificia Universidad Católica de Valparaíso, n. ${ }^{\circ}$ 31. Valparaíso.

176 Córdoba, Marcos (2019). "Mejora a favor del heredero con discapacidad en la Argentina”, en Leonardo PÉRez Gallardo (coord.). Hacia un nuevo derecho de sucesiones. Bogotá: Ibáñez.

Corral Talciani, Hernán (1994). Familia y derecho. Santiago: Universidad de los Andes.

Corral Talciani, Hernán (1998). "La protección de la vivienda familiar a favor del cónyuge sobreviviente. Panorama de derecho comparado", en Derecho sucesorio actual y adjudicación de la vivienda familiar. Cuadernos de Extensión Jurídica, n. ${ }^{\circ} 4$. Santiago.

Corral Talciani, Hernán (2005). La vivienda familiar en la sucesión del cónyuge. Santiago: Editorial Jurídica de Chile.

Del Picó Rubio, Jorge (2011). "Evolución y actualidad de la concepción de familia. Una apreciación de la incidencia positiva de las tendencias dominantes a partir de la reforma del derecho matrimonial chileno". Ius et Praxis, año 17, n. ${ }^{\circ}$ 1. Talca.

De Lama Aymá, Alejandra (2016). Libertad de testar y memorias testamentarias. Valencia: Tirant lo Blanch.

De la Fuente Linares, José Cándido Francisco Javier (2012). "La protección constitucional de la familia en América Latina". Revista del Instituto de Ciencias Jurídicas de Puebla, n. ${ }^{\circ}$ 29. Puebla.

Díez-Picazo, Luis (2008). Fundamentos del derecho civil patrimonial III. $5^{\mathrm{a}}$ ed. Pamplona: Aranzadi. 
DíAz García, Iván (2012). "Igualdad en la aplicación de la ley. Concepto, iusfundamentalidad y consecuencias". Ius et Praxis, año 18, n. ${ }^{\circ}$ 2. Talca.

Domínguez Águila, Ramón (1996). "Aspectos de la constitucionalización del derecho civil chileno". Revista de Derecho y Jurisprudencia, tomo 93, n. ${ }^{\circ} 3$. Santiago.

Domínguez Águila, Ramón (2006). "Principios del derecho sucesorio en el código de Bello y su estado actual". Revista de Derecho Universidad de Concepción, n. ${ }^{\circ}$ 219-220. Concepción.

Domínguez Águila, Ramón (2007). "Los principios del derecho sucesorio en el 'Código Civil' de Bello y su estado actual”, en Alejandro GuzMán BRITO (coord.). El Código Civil de Chile (1855-2005). Santiago: LexisNexis.

Domínguez Benavente, Ramón (1956). "Introducción al derecho sucesorio en el Código Civil”. Revista de Derecho Universidad de Concepción, n. ${ }^{\circ} 98$. Concepción.

Domínguez Benavente, Ramón y Ramón Domínguez Águila (2011). Derecho Sucesorio. $3^{\mathrm{a}}$ ed. actualizada. Santiago: Editorial Jurídica de Chile, tomo I.

Elorriaga de Bonis, Fabián (2019). "La libertad de testar y sus restricciones. Consideraciones para su eventual revisión en Chile", en Manuel BARRÍA Paredes, José Luis Diez Schwerter, Iñigo De La Maza Gazmuri, Rodrigo Momberg Uribe, Gonzalo Montory Barriga y Álvaro Vidal Olivares (coords.). Estudios de derecho privado en homenaje al profesor Daniel Peñailillo Arévalo. Santiago: Thomson Reuters.

Escribano Tortajada, Patricia (2019). "La sustitución fideicomisaria en la legítima estricta a favor del descendiente incapacitado judicialmente: algunos problemas que plantea”, en Francisco CAPILla Roncero, Manuel Espejo LeRdo DE Tejada y Francisco José Aranguren Urriza (dirs.). Las legítimas y la libertad de testar. Perfiles críticos y comparados. Navarra: Thomson Reuters/Aranzadi.

Evans de la CuAdra, Enrique (1999). Los derechos constitucionales. $2^{\mathrm{a}}$ ed. Santiago: Editorial Jurídica de Chile, tomo III.

Ferrer, Francisco (2019). "Algunos aspectos de la transmisión sucesoria ante los nuevos tiempos", en Leonardo PÉrEz GALLARDo (coord.). Hacia un nuevo derecho de sucesiones. Bogotá: Ibáñez.

Figueroa Yáñez, Gonzalo (1995). Persona, pareja y familia. Santiago: Editorial Jurídica de Chile.

Finsterbusch Romero, Christian (2016). "La extensión de los ajustes razonables en el derecho de las personas en situación de discapacidad de acuerdo al enfoque social de derechos humanos". Ius et Praxis, año 22, n. ${ }^{\circ}$. Talca.

García Acuña, Natalia (2009). El concepto de familia en la Constitución. Memoria para optar al grado de Licenciado en Ciencias Jurídicas y Sociales de la Universidad de Chile. Santiago: Universidad de Chile.

Gauché Marchetti, Ximena (2019). “De la capacidad jurídica en el Código Civil chileno. Miradas desde el derecho internacional de los derechos humanos", en Manuel Barría Paredes, José Luis Diez Schwerter, Iñigo De La Maza Gazmuri, Rodrigo Momberg Uribe, Gonzalo Montory Barriga y Álvaro 
Vidal Olivares (coords.). Estudios de derecho privado en homenaje al profesor Daniel Peñailillo Arévalo. Santiago: Thomson Reuters.

Instituto Nacional de Estadísticas (2019). "Esperanza de vida". Definiciones estadísticas, portal institucional del INE. Disponible en www.ine.cl/ineciudadano/definiciones-estadisticas/poblacion/esperanza-de-vida [fecha de consulta: 15 de marzo de 2021].

LAfaille, Héctor (1932). Curso de derecho civil. Sucesiones. Buenos Aires: Ediciones Depalma.

LATHROP, Fabiola (2017). "Constitucionalización y jurisprudencia constitucional en el derecho de familia chileno". Estudios Constitucionales, año 15, n. ${ }^{\circ} 1$. Santiago.

Lepín Molina, Cristián (2014). "Los nuevos principios del derecho de familia". Revista Chilena de Derecho Privado, n. ${ }^{\circ}$ 23. Santiago.

MARAÑón Astolfi, María (2019). "Family provisions cilegítima en el derecho anglosajón?”, en Francisco Capilla Roncero, Manuel Espejo Lerdo dE Tejada y Francisco José Aranguren Urriza (dirs.). Las legítimas y la libertad de testar. Perfiles críticos y comparados. Navarra: Thomson Reuters/Aranzadi.

Marshall Barberán, Pablo (2020). "El ejercicio de derechos fundamentales de las personas con discapacidad mental en Chile: derecho internacional, enfoques teóricos y casos de estudio". Revista de Derecho Universidad de Concepción, n. 247. Concepción.

Medina, Graciela (2019). "Principios, características y desafíos pendientes del derecho de sucesiones argentino", en Leonardo Pérez Gallardo (coord.). Hacia un nuevo derecho de sucesiones. Bogotá: Ibáñez.

Nogueira Alcalá, Humberto (2006). "El derecho a la igualdad ante la ley, no discriminación y acciones positivas". Revista de Derecho Universidad Católica del Norte, año 13, n. ${ }^{\circ}$ 2. Coquimbo.

Peñailillo Arévalo, Daniel (1968). "El principio de la igualdad en el derecho sucesorio". Revista de Derecho Universidad de Concepción, n. ${ }^{\circ}$ 143. Concepción.

Peñailillo Arévalo, Daniel (1969). "El principio de la igualdad en el derecho sucesorio (Conclusión)". Revista de Derecho Universidad de Concepción, n. ${ }^{\circ} 146$ 147. Concepción.

Peñailillo Arévalo, Daniel (2014). "La regulación constitucional de la propiedad en el Derecho Comparado". Revista de Derecho Universidad de Concepción, n. ${ }^{\circ} 235$ 236. Concepción.

Peñallillo Arévalo, Daniel (2019). Los bienes. La propiedad y otros derechos reales. Santiago: Thomson Reuters.

Peralta Fierro, Ximena e Isabel Yáñez Morales (2019). "La función social de la propiedad en la jurisprudencia del Tribunal Constitucional chileno”. Revista de Derecho Público, n. ${ }^{\circ}$ 91. Santiago.

Pérez Gallardo, Leonardo (2010). "El derecho de sucesiones en cifras: Recapitulación y pronósticos", en Leonardo Pérez Gallardo (Coord.). El derecho de sucesiones en Iberoamérica. Tensiones y retos. Bogotá/Ciudad de México/Madrid/ Buenos Aires: Temis/Ubijus/ Reus/ Zavalia. 
Ramos Pazos, René (1995). "De los bienes familiares". Revista de Derecho Universidad de Concepción, n. ${ }^{\circ}$ 198. Concepción.

Ramos Pazos, René (2006). "Derecho de familia, ciento cincuenta años después". Revista de Derecho Universidad de Concepción, n. ${ }^{\circ}$ 219-220. Concepción.

Ramos Pazos, René (2007). Derecho de familia. $7^{\mathrm{a}}$ ed. Santiago: Editorial Jurídica de Chile, tomo I.

Ríos Álvarez, Lautaro (1987). "El principio constitucional de la función social de la propiedad". Revista de Derecho y Jurisprudencia, tomo 84, n. ${ }^{\circ}$ 2. Santiago.

Rioseco Enríquez, Emilio (1956). "El Código Civil y la evolución del derecho de familia". Revista de Derecho Universidad de Concepción, n. ${ }^{\circ} 98$. Concepción.

Salah Abusleme, María Agnes (2019). "Tres visiones de la igualdad para el derecho sucesorio", en Esteban Pereira Fredes (coord.). Fundamentos filosóficos del derecho civil chileno. Santiago: Rubicón.

SALOMÓn, Marcelo (2011). Legítima hereditaria y constitución nacional. Examen constitucional de la herencia forzosa. Córdoba: Alveroni Ediciones.

Soto KLoss, Eduardo (1994). "La familia en la Constitución Política”. Revista Chilena de Derecho, vol. 21, n. ${ }^{\circ}$ 2. Santiago.

TAPIA Rodríguez, Mauricio (2005). Código Civil 1855-2005. Evolución y perspectivas. Santiago: Editorial Jurídica de Chile.

VAQUer Aloy, Antoni (2018). Libertad de testar y libertad para testar. Santiago: Olejnik.

Veloso Valenzuela, Paulina (1998). "Nuevos principios del derecho de familia en función, principalmente, de la normativa internacional que emana de los tratados de derechos humanos". Revista de Derecho de la Pontificia Universidad Católica de Valparaíso, n. ${ }^{\circ}$ 19. Valparaíso.

Verdugo Marinkovic, Mario, Emilio Pfeffer Urquiaga y Humberto Nogueira Alcalá (1994). Derecho constitucional. Santiago: Editorial Jurídica de Chile, tomo I.

Walker Silva, Nathalie (2019). "El anacronismo de las asignaciones forzosas y el necesario reconocimiento de la libertad para testar en Chile", en Esteban Pereira Fredes (coord.). Fundamentos filosóficos del derecho civil chileno. Santiago: Rubicón.

\section{Jurisprudencia citada}

Control de constitucionalidad al proyecto de Ley sobre Votaciones Populares y Escrutinios (1988): Tribunal Constitucional, 5 de abril de 1988, rol n. ${ }^{\circ}$ 53-88, control de constitucionalidad respecto del proyecto de ley orgánica constitucional sobre votaciones populares y escrutinios. Disponible en www. tribunalconstitucional.cl [fecha de consulta: 1 de marzo de 2021].

Requerimiento de inconstitucionalidad al proyecto de ley sobre reajuste extraordinario de 10\% de las pensiones (1995): Tribunal Constitucional, 31 de julio 
de 1995 , rol n. ${ }^{\circ} 219-95$, requerimiento de inconstitucionalidad respecto a la tramitación del proyecto de reajuste extraordinario de un 10\% a las pensiones que indica y un aumento adicional a la educación. Disponible en www. tribunalconstitucional.cl [fecha de consulta: 5 de marzo de 2021].

Requerimiento de inconstitucionalidad del Colegio de Abogados al art. 595 COT (2009): Tribunal Constitucional, 29 de julio de 2009, rol n. ${ }^{\circ}$ 1254-08, requerimiento de inconstitucionalidad del Presidente del Colegio de Abogados de Chile, señor Enrique Barros Bourie, en representación de dicha entidad, respecto del texto íntegro del artículo 595 del Código Orgánico de Tribunales. Disponible en www.tribunalconstitucional.cl [fecha de consulta: 12 de marzo de 2021].

Requerimiento de inaplicabilidad de J. C. y otros al art. 10, letra h, de la Ley N 20.285 (2011): Tribunal Constitucional, 21 de junio de 2011, rol n. ${ }^{\circ} 1732-10$, requerimiento de inaplicabilidad por inconstitucionalidad presentado por Jorge Cabezas Villalobos y otros trabajadores de Televisión Nacional de Chile al artículo 10 h) de la Ley sobre Acceso a la Información Pública. Disponible en www.tribunalconstitucional.cl [fecha de consulta: 12 de marzo de 2021].

Fisco de Chile con Molibdenos y Metales S.A. y otra (2014): Corte Suprema, 1 de septiembre de 2014, rol n. ${ }^{\circ}$ 15996-2013, Id. Westlaw: CL/JUR/6175/2014.

Molinera del Norte S.A. con Ministerio de Vivienda y Urbanismo (2015): Tribunal Constitucional, 27 de enero de 2015, rol n. ${ }^{\circ}$ 2644-2014, Id. Westlaw: $180 \quad$ CL/JUR/612/2015.

P. R. con P. S. (2015): Corte de Apelaciones de Concepción, 30 de octubre de 2015, rol n. ${ }^{\circ}$ 448-2015, Id. Westlaw: CL/JUR/6640/2015.

Z. A. con Z. Z. (2016): Corte de Apelaciones de Santiago, 7 de enero de 2016, rol n. ${ }^{\circ}$ 2793-2015, Id. Westlaw: CL/JUR/87/2016.

S. D. con Armada de Chile (2016): Tribunal Constitucional, 5 de mayo de 2016, rol n. ${ }^{\circ}$ 2759-14, Id. Westlaw: CL/JUR/3282/2016.

Minera Pampa Fénix S.C.M. con Fisco de Chile (2016): Corte Suprema, 5 de septiembre de 2016, rol n. ${ }^{\circ}$ 19081-2015, Id. Westlaw: CL/JUR/6185/2016.

Agrícola San Isidro Limitada con Dirección General de Aguas (2016): Tribunal Constitucional, 15 de diciembre de 2016, rol n. ${ }^{\circ}$ 2881-15, Id. Westlaw CL/ JUR/8376/2016.

Z. L. con Z. L. (2018): Corte Suprema, 21 de noviembre de 2018, rol n. ${ }^{\circ} 3613-$ 2018, Id. Westlaw: CL/JUR/6511/2018.

C. B. con G. M. (2019): Corte Suprema, 20 de febrero de 2019, rol n. ${ }^{\circ}$ 3411-2018, Id. Westlaw: CL/JUR/904/2019.

V. V. con S. O. (2019): Corte Suprema, 28 de noviembre de 2019, rol n. ${ }^{\text {o } 20922-}$ 2018, Id. Westlaw: CL/JUR/11924/2019.

Banco de Chile con Consejo de Monumentos Nacionales y otro (2020): Corte Suprema, 10 de agosto de 2020, rol n. ${ }^{\circ}$ 26076-2019, Id. Westlaw: CL/JUR/ 69351/2020. 
N. N. con N.bN. (2021): Corte de Apelaciones de Santiago, 5 de enero de 2021, rol n. ${ }^{\circ}$ 301-2020, Id. Westlaw CL/JUR/3417/2021.

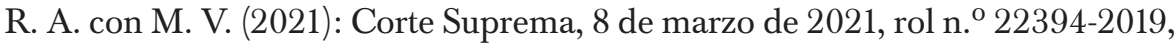
Id. Westlaw CL/JUR/45090/2021.

C. C. con P. M. (2021): Corte Suprema, 22 de marzo de 2021, rol n. ${ }^{\circ}$ 99469-2020, Id. Westlaw CL/JUR/46350/2021.

SIGLAS Y ABREVIATURAS

art. artículo

arts. artículos

CE Constitución española

coord. coordinador

coords. coordinadores

cons. considerando

COT Código Orgánico de Tribunales

dirs. directores

ed. edición

inc. inciso

LGDJ Libraire Generale de Droit Juris

n. ${ }^{\circ}$ número

p. página

pp. páginas

vol. volumen

www World Wide Web 